\title{
Compreensão e afetividade: $o$ fã dentro da lógica comercial do Big Brother Brasil
}

\author{
Bruno Campanella $^{1}$
}

\begin{abstract}
Resumo: Este artigo investiga alguns aspectos relacionados à recepção de conteúdos midiáticos exibidos em múltiplas plataformas. Tomando o reality show Big Brother Brasil como exemplo, o autor sugere que o processo de compreensão do texto deste produto midiático é, em parte, influenciado pela(s) mídia(s) utilizada(s) pela audiência. Isto ocorre porque a representação do cotidiano dos participantes do programa sofre maior ou menor interferência dos produtores, dependendo da mídia analisada. Estas diferenças, produzidas dentro de uma lógica comercial, são particularmente percebidas dentro das comunidades de fãs, pois estas possuem um maior senso de proximidade em relação aos eventos da casa. Como evidência para os argumentos propostos, o presente trabalho conjuga alguns relatos de fãs com uma análise do formato do Big Brother Brasil.
\end{abstract}

Palavras-chave: Big Brother; multiplataforma; recepção; compreensão; proximidade.

\begin{abstract}
This article dwells on some aspects related do the reception of media content shown on multiple platforms. Taking the reality show Big Brother Brasil as an example, the author suggests that the process of comprehension of this text is partially influenced by the kind(s) of media used by the audience. These differences, produced within a commercial logic, are particularly noticed within the fan communities due to their sense of proximity to the events in the house. As evidence for the arguments proposed, this paper presents some accounts done by fans of the show, while, at the same time, it makes an analyses of its format.
\end{abstract}

Key words: Big Brother Brazil; multi-platform; reception; comprehension; proximity.

\section{Introdução}

Os estudos de audiência foram influenciados por inúmeras tradições ao longo do século XX. Dentre as principais, poderíamos destacar a teoria crítica (Escola de Frankfurt), a teoria dos efeitos (estudos behavioristas), os usos e gratificações (teorias funcionalistas), e os estudos culturais ${ }^{2}$ (MORLEY, 1992). Embora cada uma delas tenha tido o papel de estabelecer importantes questionamentos quanto à relação do indivíduo

\footnotetext{
${ }^{1}$ Bruno Campanella é mestre em Transnational Communications and the Global Media pelo Goldsmiths College, University of London, e doutorando em comunicação e cultura pela ECOUFRJ.

2 Alguns autores sugerem diferentes classificações. Jensen e Rosengren, por exemplo, enumeram as seguintes tradições como as mais importantes dos estudos de audiência: teoria dos efeitos, usos e gratificações, crítica literária, estudos culturais e estudos de recepção (JENSEN \& ROSENGREN 1990). Entretanto, não está no escopo deste trabalho a análise de tais diferenças de perspectivas.
} 
com as mídias, a tradição dos estudos culturais foi aquela que adquiriu maior proeminência nas últimas décadas. Através do trabalho seminal de Stuart Hall, a atenção ao processo de negociação de sentidos dos textos midiáticos ganhou grande destaque. A teoria da codificação/ decodificação proposta por Hall, na qual as mensagens dependendo do subgrupo social estudado - poderiam ser decodificadas de acordo com o sentido proposto pelo produtor do texto (leitura referencial), de maneira a preservar parte do seu sentido original (leitura negociada), ou de maneira oposta (leitura opositora) foi fundamental para o desenvolvimento dos estudos de recepção (HALL, 1980). David Morley foi quem aplicou pela primeira vez o modelo de Hall em sua pesquisa envolvendo o programa televisivo inglês Nationwide (MORLEY, 1980). Em seu trabalho, Morley estava particularmente interessado em entender a influência do contexto socioeconômico do receptor para o processo de significação do texto. A partir daí, outros trabalhos de recepção foram feitos com o objetivo de aprofundar a investigação dos fatores que influenciam este processo (ANG, 1985; RADWAY, 1984; FISKE, 1987). Em comum, eles compartilham a premissa de que o texto é a peça fundamental para o entendimento da circulação de sentidos no momento da recepção. Livingstone sugere, inclusive, que se deve distinguir o momento de compreensão de um texto - referente ao sentido denotativo/ literal -, para aquele de sua interpretação referente ao sentido conotativo/ associativo. A autora argumenta que esta separação se faz especialmente pertinente quando os textos em questão são abertos, pois, nestes casos, seria possível observar uma maior divergência entre estes processos (LIVINGSTONE, 1998).

Entretanto, o desenvolvimento das tecnologias digitais permitiu a criação de novos tipos de conteúdo com características multiplataforma - ou seja, conteúdos que são exibidos em diferentes mídias. Porém, tais produtos - frequentemente criados com o objetivo de se encurtar a distância com o mercado consumidor - trouxeram novos desafios para os estudos de recepção. Criou-se, por exemplo, o problema de se encontrar uma unidade textual entre estas plataformas que seja capaz de caracterizar um núcleo de significação homogêneo. O próprio processo de compreensão se torna mais complicado, uma vez que passamos a ter vários textos distintos definindo um mesmo produto midiático. 
Este artigo utiliza o exemplo do reality show Big Brother para explorar algumas destas questões, e das suas conseqüências, tanto para a sua audiência, quanto para os seus produtores. Para isso, é feita uma análise do formato do programa, conjugada ao exame de alguns depoimentos resultados de uma pesquisa na internet com fãs do Big Brother Brasil, realizada durante a sétima edição do programa no ano de 2007.

\section{O Big Brother}

Apesar de já existirem inúmeros produtos midiáticos que se caracterizam pelo seu conteúdo multiplataforma, o programa de reality show Big Brother conseguiu, como nenhum outro, se adaptar de forma completa a este novo ambiente. O programa em questão foi criado como um formato a ser vendido para canais de televisão no final dos anos 90 pela produtora holandesa Endemol. Porém, a sua bem sucedida venda para diversos países (quebrando recordes de audiência em muitos deles), aliada à sua capacidade de se adaptar à nova realidade da convergência midiática, acabou resultando na venda da própria Endemol para o Grupo Telefônica por $€ 5.5$ bilhões no ano de 2000 (BAZALGETTE, 2005).

No Brasil, o reality show também alcançou grande sucesso comercial na grade de exibição da Rede Globo, detentora dos seus direitos em território nacional. Além da receita gerada com a venda de publicidade para a Globo e para o canal Multishow, o Big Brother sinalizou um novo caminho de diversificação das receitas, possibilitado pela sua exibição em múltiplas plataformas. Conforme explorado em outro trabalho (CAMPANELLA, 2007a), este impacto se deu tanto no canal Premiere, explorado em formato pay-per-view, como no mundo virtual, onde a exibição do programa alavancou o número de acessos ao portal Globo.com. Isto sem mencionar o fato de este reality show ter inspirado a criação de um grande número de comunidades, fórums, blogs etc., onde ocorrem permanentes discussões acerca da rotina da casa, assim como do destino dos seus ex-participantes, quando estes deixam o programa ${ }^{3}$. O produto Big Brother, desta maneira, passa a transcender os domínios estabelecidos pelos seus criadores.

\footnotetext{
${ }^{3}$ Estes(as) ex-participantes do Big Brother, se tornam produtos de consumo neles mesmos, e passam a fazer parte de uma 'economia da celebridade'. Os mais bem sucedidos conseguem prolongar sua existência midiática participando de programas de auditório, ensaios fotográficos, editoriais em revistas, e até mesmo deslanchando carreiras no meio artístico como atores, apresentadores e cantores (Campanella 2007a; Freire Filho 2007a).
} 
Podemos afirmar, portanto, que mesmo sendo transmitido em canal de TV aberta, não seria prudente reduzir o Big Brother a um programa eminentemente de televisão. O correto seria dizer que ele também é um programa televisivo, uma vez que este reality show, em sua versão brasileira ${ }^{4}$, é transmitido em TV aberta, TV paga, payper-view, internet e telefonia celular. Os números referentes à sétima edição da versão nacional do programa atestam a sua força nestas outras mídias. Esta edição bateu as anteriores em todas as plataformas alternativas. Na TV paga, por exemplo, o Multishow alcançou a maior audiência da história da TV por assinatura no Brasil com 7,5 pontos em fevereiro de 2007 (O GLOBO - 13/03/2007). Somente no primeiro mês de exibição desta edição do programa, 13 milhões de pessoas visitaram a página virtual do Big Brother Brasil, acessando os vídeos disponíveis 71 milhões de vezes, um aumento de 772\% se comparado à edição anterior do reality show (O GLOBO - 19/02/2007).

Entretanto, estes números nada dizem sobre as diferenças entre as versões exibidas por estas plataformas, principalmente no que diz respeito aos variados graus de edição e mediação. A versão veiculada pela Rede Globo, por exemplo, é a mais editada de todas. Nela pode-se perceber um esforço dos produtores na criação de uma maior coerência narrativa dentro do cotidiano dos integrantes da casa. Estes últimos são frequentemente retratados como parte de sub-grupos bem caracterizados (grupo do bem, grupo do mal, grupo dos pobres, grupo dos loiros etc.), participando de enredos consistentes que se desenvolvem ao longo da duração da série. Podemos identificar uma visível influência do gênero da teledramaturgia nacional na linguagem utilizada para retratar estas tramas (conspirações, conquistas amorosas etc.). Esta versão é constituída de programas diários de pequena ou média duração com algumas 'entradas' ao vivo sempre intermediadas por um apresentador encarregado de direcionar as conversas -, conjugadas com vídeos contendo pequenos resumos dos principais acontecimentos da casa, além de animações de cunho humorístico relacionadas ao cotidiano dos participantes. Já o canal de TV paga Multishow, pertencente à Globosat, exibe imediatamente após o término da transmissão em TV aberta um flash ao vivo da casa

\footnotetext{
${ }^{4}$ Embora ocorram variações, como por exemplo, na Inglaterra, onde o programa também é oferecido por um de seus patrocinadores em uma versão para iPod, as suas principais mídias são internet, TV aberta e pay-per-view.
} 
com duração média de 20 minutos $^{5}$. A versão em pay-per-view transmite imagens do confinamento 24 horas por dia, durante todo o período de duração da produção. O assinante desta plataforma tem acesso a dois canais com imagens ao vivo da casa. Um deles é um mosaico mostrando simultaneamente imagens de quatro câmeras diferentes, enquanto o outro exibe em tela inteira uma das quatro imagens do mosaico. Pela internet, os assinantes do Globo Media Center têm acesso às câmeras transmitidas pelo pay-per-view, além de duas outras exclusivas para o assinante virtual. Os não assinantes deste serviço também podem acompanhar o programa pela internet, por meio da página oficial do Big Brother que traz notícias permanentemente atualizadas dos acontecimentos da casa em formato de texto. Esta página também disponibiliza gratuitamente alguns vídeos selecionados pelos produtores com imagens previamente transmitidas, além de oferecer espaços para fóruns e blogs de discussão sobre o reality show. Por último, deve-se mencionar o acordo entre a Rede Globo e as principais operadoras de celular no país que permite aos fãs do programa acompanhar o áudio direto de todos os ambientes da casa do Big Brother, ou mesmo do microfone de qualquer um dos participantes.

Como conseqüência das diferenças entre as múltiplas plataformas de transmissão do programa, a própria definição do que é o Big Brother, e qual é o seu 'texto midiático', passa a ser uma questão central. Conforme indicam algumas pesquisas que realizei em fóruns de discussão na internet, durante a sétima versão nacional do programa, a falta de homogeneidade nas narrativas apresentadas por estas plataformas desperta grande polêmica acerca da compreensão e da interpretação dos acontecimentos da casa. $\mathrm{O}$ fato de cada uma das mídias oferecer um diferente tipo de acesso à rotina dos participantes dificulta a percepção do Big Brother como um texto fechado.

Deve-se, entretanto, salientar que esta dificuldade não está necessariamente relacionada a uma característica imanente ao texto, onde seus signos podem levar o seu leitor a diferentes tipos de compreensão do mesmo, o que o caracterizaria como um texto aberto (ECO, 1989). No caso deste produto multiplataforma, a dificuldade em se atingir um denominador comum quanto à sua compreensão se dá pelas diferentes formas que este pode adquirir dependendo da(s) mídia(s) utilizada(s) no processo de recepção.

\footnotetext{
${ }^{5}$ Tanto a Rede Globo, quanto o Multishow também exibem programas semanais onde os acontecimentos na casa são discutidos e reverberados com os fãs do programa.
} 
Sonia Livingstone sugere que o processo de recepção da audiência é decorrente de duas ações distintas, que podem ocorrer concomitantemente. A de compreensão do texto, que seria ligada a 'fatores textuais', ou, nos termos de Hall, a sua 'leitura preferencial'. E a segunda ação seria a de interpretação do texto. Neste caso, o contexto do leitor, que abrange fatores ligados ao seu capital cultural, a sua posição sóciodemográfica, os seus recursos sóciocognitivos entre outros, teriam um papel preponderante na criação de sentido. Nestas duas ações, tanto os fatores textuais quanto os de contexto não devem ser vistos como completamente determinantes, porém, como fazendo parte de um processo dinâmico e aberto a contradições, agenciamento, polissemia, ambigüidade etc. (LIVINGSTONE, 1998).

Numa telenovela, por exemplo, não é difícil imaginar que a interpretação de uma dada situação irá depender, em parte, de como ela é compreendida pela audiência. Livingstone, entretanto, relembra o estudo de Owens, Bower, \& Black (1979) para argumentar que esta ordem também pode ser invertida, na medida em que o prévio conhecimento de possíveis motivações de um personagem, em um dado evento dentro de uma trama, pode sugerir diferentes compreensões do mesmo.

No caso do Big Brother, a apresentação da subjetividade de um dado participante da casa, assim como de suas motivações, dependerá, em grande parte da mídia, ou da combinação de mídias, utilizada pela audiência nos seus momentos de recepção do programa. Como já foi visto acima, as versões ao vivo do Big Brother via pay-per-view, internet e telefonia celular permitem o acompanhamento segundo-asegundo do cotidiano dos participantes, suas discussões, confidências, momentos de ócio etc. Enfim, a audiência tem acesso a um extenso número de situações que a ajudam a construí-los como personagens.

De acordo com Bakhtin, este personagem - este outro presente na nossa realidade social - se constitui para nós através da linguagem. Ele se forma a partir do cotidiano, no contato dialógico com a alteridade e com o mundo que o cerca. Nas palavras de Bakhtin:

O falante não é um Adão, e por isso o próprio objeto do seu discurso se torna inevitavelmente um palco de encontro com opiniões de interlocutores imediatos (na conversa ou na discussão sobre algum acontecimento do dia-a-dia) ou com pontos de vista, visões de mundo, correntes, teorias, etc" (BAKHTIN, 2003 :300) 
Ou seja, o falante é dinamicamente constituído pelo uso das palavras que utiliza no seu diálogo com o mundo em que habita. Isto ocorre, pois estas palavras não são puras, ou virgens, elas trazem o peso dos seus usos passados e futuros. Ao mesmo tempo, elas geram atitudes responsivas dos interlocutores, dentro de um processo constitutivo de uma realidade social.

Mesmo habitando um ambiente artificialmente construído para a apresentação do seu eu, ambiente este que é, ainda por cima, mediado por câmeras de televisão e microfones, o participante do Big Brother se torna real para a audiência através dos diálogos que mantém com os outros integrantes da casa, assim como com a sua interação com este ambiente. Apesar de não haver um contato presencial com a audiência, uma relação dialógica se forma, onde o participante se torna, para a audiência/ leitor, um sujeito que desperta expectativas e aspirações.

O que acontece então, se a percepção que temos destes personagens, construída através do acompanhamento direto do seu cotidiano vivido na casa, contrasta com as suas construções apresentadas na versão em TV aberta? É exatamente esta discrepância que podemos perceber como importante foco de debate nos fóruns dos fãs que acompanham o Big Brother em diversas mídias. A opção da Rede Globo pela produção de uma versão do Big Brother para TV aberta inspirada num gênero familiar à audiência, como é o caso da telenovela, deve ser vista dentro de uma lógica de mercado. Dentro deste contexto, é possível relacionar a maneira como os personagens são construídos - com papéis bem definidos dentro de tramas relativamente simples -, com a tentativa de facilitar a compreensão de uma versão dos acontecimentos da casa por parte da audiência, potencializando a polarização de opiniões. Desta maneira, toda a estrutura do jogo baseada nas indicações para os paredões e subseqüente eliminação através dos votos do público ganharia um maior apelo comercial.

Pelo menos, esta parece ser a percepção de um grande número de fãs do reality show que participam das discussões em blogs e fóruns on-line. Um dos administradores 
do blog BBB.link ${ }^{6}$, por exemplo, apresentou a sua insatisfação numa suposta tentativa da Globo em transformar o reality show em questão numa narrativa 'novelesca,7:

- [...]Cremos que muitos que acompanharam o que rolou do Paredão de Terça até o programa da liderança desta Quinta, tiveram a comprovação que o que se vê pelo PPV está muito longe da realidade do que é mostrado pela TV aberta nas edições do BBB7. E mais... justamente o que seria o mais interessante e polêmico não é mostrado para o público que assiste pela Globo na TV aberta. Nisto temos dois grupos em prejuízo... o público do PPV que sempre se vê frustrado entre a realidade do cativeiro e o que é mostrado na TV aberta... o público da TV aberta que não faz a mínima idéia das situações reais que acontecem no cativeiro do BBB7, e para piorar é este público, que é a grande maioria dos que acompanham o BBB7, que é induzido a ver uma novela de tendência irreal, até surreal, do que é o verdadeiro jogo que acontece na Casa do BBB7, e mesmo do que é um reality show.

02/Fevereiro/2007 - 02:15

Em outro comentário feito no fórum BBB.Lua ${ }^{8}$, um dos mais populares entre os fãs do programa, também podemos perceber o descontentamento na maneira como os integrantes da casa são apresentados nas edições realizadas pela Globo:

- [...]Não há nada mais claro do que o que está acontecendo nesse BBB. Eles [os produtores] realmente afetam totalmente a credibilidade do programa fazendo essa mudança absurda da realidade nas edições. Até quem não está assistindo pelo PPV já começa a perceber que há um favorecimento escandaloso ao trio ${ }^{9}$.

Prapensar $^{10}$ - 14/Fevereiro/2007 13:19:31

Boninho, o diretor do programa no Brasil, afirma que "nos outros países, eles [os produtores] simplesmente mostram o que acontece. Nossa equipe bola vídeos, desenhos animados, clipes com piadas, vinhetas. [...] Fazemos uma mistura da cultura que temos da dramaturgia, que aplicamos bem no programa, com o lado bem-humorado e escrachado do brasileiro” (O Globo - 08/01/2007). Ou seja, com o objetivo de adaptar o

\footnotetext{
${ }^{6}$ Este blog (http://bbblinks.blogger.com.br/) saiu do ar em outubro de 2007. Em seu lugar, os seus administradores criaram dois outros blogs, o http://teleblogger.blogger.com.br/, e o http://tors-jebal.blogspot.com/.

${ }^{7}$ Os comentários de fãs apresentados neste trabalho foram feitos em espaços virtuais públicos, abertos para todos os usuários da internet, tais como fóruns e blogs, Eles são reproduzidos aqui preservando o mesmo formato em que foram originalmente escritos (ex: negrito, letras maiúsculas/ minúsculas, pontuação etc.). O conteúdo entre colchetes [], foi acrescentado pelo autor deste artigo.

${ }^{8} \mathrm{http}: / / \mathrm{bbb} . l u a . c o m /$

${ }^{9} \mathrm{O}$ trio referido pelo fã (Fani, Alemão e Siri) protagonizou um suposto triangulo amoroso que teve muito apelo junto à audiência da sétima versão do Big Brother Brasil.

10 'Prapensar' é o login adotado pelo fã do Big Brother que publicou o comentário acima. Geralmente, os fãs que participam dos fóruns de discussão do programa não utilizam os seus nomes verdadeiros.
} 
formato do Big Brother ao gosto do público brasileiro, os produtores do reality show nacional optaram por transformar a versão em TV aberta do programa num gênero híbrido, ao invés de simplesmente editar uma versão resumida dos acontecimentos da casa. Como conseqüência, aqueles membros da audiência que acompanham o Big Brother por diferentes mídias, correm o risco de receber informações conflitantes quanto ao texto que deve ser decodificado. Diferentemente de um filme ou uma telenovela, a 'leitura preferencial' deste reality show, é totalmente dependente da(s) plataforma(s) utilizada(s) para seu consumo. Isto significa que não faz sentido pensar o fenômeno do Big Brother sob o ponto de vista de uma de suas plataformas somente. Tincknell e Raghuram resumem bem esta percepção, ao afirmar que:

[O Big Brother] ... não era um texto único, num sentido simples, porém, ao mesmo tempo, também não era constituído por textos fragmentados e diferentes. Ao invés disso, a combinação de nódulos textuais trabalhando num relacionamento complexo parecia confirmar que havia algo que podia ser chamado de "Big Brother", mas que não era confinado ou limitado a um programa televisivo. (Tinknell \& Raghuram 2002: 213)

Enquanto que nos estudos tradicionais de televisão o gênero televisivo é visto como ponto de partida para a construção de uma relação entre o conteúdo e a audiência (MACHADO, 2007; HANSEN et al. 1998), no caso do Big Brother esta função se problematiza. Isto porque, o conceito de gênero se refere, em parte, aos limites de compreensão de um texto. Um programa do gênero jornalístico, por exemplo, deve ser percebido como uma tentativa de se apresentar, da forma mais fiel possível, algum acontecimento relacionado à realidade cotidiana. De maneira oposta, um produto do gênero da telenovela não se propõe a relatar com exatidão situações da vida de uma cidade ou de um país. Ele pode até fazer referências a algum acontecimento real, porém há um entendimento dentro da audiência de que não existe um compromisso com a apresentação exata e neutra de fatos acontecidos. Porém, como vimos acima, este ‘contrato’ com a audiência não se concretiza no caso do Big Brother.

Para enfrentar este problema, François Jost propõe que abandonemos a tentativa de entender a relação entre o autor da obra e o seu leitor através do 'contrato’ do gênero. Para Jost, esta perspectiva se limita a considerar o leitor como um sujeito livre e capacitado para interpretar o texto dentro de certas restrições impostas pelo próprio texto. Porém, no caso do Big Brother, esta proposição não nos ajuda a compreender as 
tensões que ocorrem nesta relação. No seu lugar, o autor francês sugere um modelo que leve em conta o fato do texto ser um produto a ser consumido dentro de uma lógica comercial onde o lucro tem um papel fundamental. Para tanto, devemos passar a entender o gênero como uma promessa feita pelo produtor. Esta faria parte de uma estratégia de mercado onde o produto midiático seria acompanhado de inúmeros 'paratextos' que teriam a finalidade de prometer à audiência diferentes prazeres simbólicos (JOST 2004 :107). Chamadas em intervalos comerciais, anúncios em jornal, páginas na internet, promoções cruzadas em outros programas televisivos, são alguns dos 'paratextos' utilizados pela Rede Globo para realizar esta tarefa no caso do Big Brother Brasil.

Para Jost, a especificidade deste reality show reside no fato dele estar posicionado de maneira eqüidistante aos três pólos definidores de um programa televisivo. São eles: a realidade, a ficção e o jogo. Ao analisar a primeira edição do Loft Story (o nome adotado pelos produtores do Big Brother francês), Fraçois relembra que o canal M6 fundamentou a campanha de lançamento do reality show na promessa de fazer um programa que estivesse em contato com a realidade como nenhum outro anterior. As 26 câmeras espalhadas na casa, filmando 24 horas por dia, seriam rapidamente esquecidas pelos integrantes do Loft Story, diziam os produtores. Com isso, os participantes passariam a agir de maneira realmente autêntica.

O problema é que esta ênfase na realidade trouxe diversas críticas da imprensa, que comparava o ambiente do programa a um campo de concentração. Os integrantes da casa eram vistos como prisioneiros dentro de um experimento voyerístico. Como conseqüência, a direção do canal resolveu direcionar seus esforços de marketing na promoção do resumo diário de 12 minutos, na esperança de que a 'leveza’ desta versão mudasse o tom das críticas. O objetivo era eliminar os momentos monótonos, ou de pouco interesse, vividos na casa, adotando um estilo de narrativa que se aproximasse do ficcional onde as brincadeiras e romances ganhariam destaque. Porém, para que o programa tivesse um maior sucesso no horário nobre os produtores também começaram a focar na interatividade oferecida pelo Loft Story. Neste novo movimento, o reality show passou a ser 'vendido' como um jogo interativo onde a audiência teria papel fundamental no desenvolvimento do seu roteiro e desfecho final (ibid :111- 113). 
A identificação destas 3 fases distintas da promoção do Big Brother francês mostra diferentes promessas sendo feitas à audiência. Neste exemplo, os interesses dos produtores direcionaram a maneira como o programa foi apresentado a um público que ainda não tinha familiaridade com o formato. Iniciando na tele-realidade, passando pela 'ficção real', e terminando no jogo interativo, o Big Brother transitou entre os três vértices constitutivos da tradição televisiva num relativo curto espaço de tempo.

Percebe-se, entretanto, que esta elasticidade do programa cria conflitos junto à audiência no que diz respeito à sua compreensão. No Brasil, onde o Big Brother já está em sua oitava edição, ele continua gerando controvérsias em relação ao conteúdo exibido em suas diferentes plataformas. Embora Jost não faça uma diferenciação explícita entre as promessas feitas em relação a cada uma delas no caso francês, os comentários dos fãs exemplificados acima demonstram ser este um foco de tensão na versão nacional do reality show.

Existe, porém, uma outra variável que deve ser levada em conta quando analisamos a natureza desta tensão entre produtor, conteúdo e audiência. Estamos nos referindo ao conceito de 'propriedade’ do programa. A transmissão do Big Brother feita em diversas mídias - algumas permitindo um contato mais próximo da audiência com o cotidiano da casa - e a possibilidade de interferência nos seus rumos através das votações proporciona a essa audiência uma sensação de controle em relação ao programa sem precedentes. Deve-se notar que este fenômeno não é novo aos olhos do mundo acadêmico. Já existe uma longa tradição de trabalhos analisando as relações afetivas dos fãs com produtos culturais diversos, tais como filmes, livros, séries televisivas, bandas de música, celebridades etc. (FREIRE FILHO, 2007b; GRAY et al. 2007; HARRIS \& ALEXANDER 1998; HILLS, 2002; JENKINS, 1992; LEWIS, 1992). O que diferencia o Big Brother destes outros produtos é o fato de este reality show ser explicitamente concebido, tanto em termos de conteúdo, como nas possibilidades de interação oferecidas, de maneira a incrementar tais relações ao máximo.

Começando pelo processo de imposição de tarefas aos confinados na casa ${ }^{11}$, passando pela eliminação semanal dos mesmos, a participação da audiência é fundamental para o andamento do programa. Em ambos os casos, o público é quem

\footnotetext{
${ }^{11}$ Chamado de Big Boss.
} 
determina o que deve ser feito ${ }^{12}$. Porém, a oitava edição do Big Brother Brasil foi ainda mais longe. A própria responsabilidade pela escolha dos participantes desta edição foi compartilhada com os fãs. Os aspirantes à casa do Big Brother foram incentivados pela produção a criar blogs pessoais contendo vídeos, fotos e depoimentos. Estes, por sua vez, deveriam ser avaliados por usuários da internet, que julgariam quem mereceria fazer parte do reality show. Os candidatos com maior votação, e melhor avaliação ${ }^{13}$, ganhavam destaque no ranking organizado pela produção. Em resumo, desde a seleção dos participantes do Big Brother, até a escolha do vencedor do programa - meses depois -, a audiência é convocada a participar de todo o processo.

Também é importante lembrar que a página oficial na internet, assim como o portal de celular do reality show, foram pensados de maneira a acomodar discussões entre os fãs sobre os acontecimentos da casa. No site oficial, por exemplo, pode-se encontrar chats, forums, e até mesmo links para blogs de fãs do Big Brother ${ }^{14}$. De maneira semelhante, através do portal de celular pode-se conversar com diversos outros entusiastas do programa.

Além do mais, ao ajudar em sua construção, o fã o está consumindo simultaneamente, seja pagando pela ligação do celular, na qual a Globo tem participação, seja gerando volume de acesso na página da internet, que é revertido em receita publicitária para o site.

O papel das plataformas de transmissão do reality show, tanto a televisão em suas diferentes versões, a internet, quanto a telefonia celular, devem, portanto, ser interpretadas de acordo com as possibilidades que essas oferecem para a relação afetiva do fã com o Big Brother. Relação esta, que está intimamente ligada a um sentimento de

\footnotetext{
${ }^{12}$ Na versão espanhola do programa o público escolhe até a condição climática durante a semana dentro da casa. Até chuva pode ser criada artificialmente no Big Brother espanhol.

${ }^{13}$ Além da simples votação sim/ não, referente ao desejo de ver a participação do candidato em questão no programa, os blogs também permitem avaliação do perfil deste candidato de acordo com categorias pré-concebidas pela produção do Big Brother. Estas categorias, inspiradas na cultura jovem, tentam reter o universo das gírias, utilizando, basicamente, dois grupos de classificação: aquelas ligadas ao grupo do flerte/ 'azaração' (pra casar, espetáculo, delícia, sem sal etc.), e o grupo da característica de personalidade/ 'zoação' (mala, sem noção, gente boa, figuraça etc.).

${ }^{14}$ Esta interação entre produtores e fãs dentro do mundo virtual é cada vez mais comum, argumenta Mark Andrejevic. Painéis online de discussão, blogs, fóruns e outros ambientes virtuais estão sendo utilizados pela indústria para aumentar o interesse dos fãs, ao mesmo tempo em que para receber feedback destes em relação aos programas produzidos (ANDREJEVIC, 2008).
} 
propriedade sobre o programa. Os próprios comentários dos fãs exemplificados acima demonstram a insatisfação destes quando percebem que a versão reproduzida em uma das plataformas do reality show não está sendo fiel às suas expectativas. Este sentimento só é possível, pois o produtor do Big Brother oferece o acesso sem cortes à rotina da casa através de plataformas alternativas.

Isto nos leva a uma constatação reveladora. Ao mesmo tempo em que o formato foi desenvolvido, e é continuamente modificado de maneira a criar uma crescente parceria com a audiência, ele também passa a sofrer um maior escrutínio desta. Principalmente, no que diz respeito às intervenções realizadas pelos produtores. Por vezes, o próprio papel do mediador do programa se torna alvo de críticas pelos fãs, conforme o comentário abaixo exemplifica ${ }^{15}$.

- Pedro Bial fez mais uma vez as intervenções extemporâneas e tendenciosas, buscando influenciar decisões dentro da casa, como se fosse um jogador a mais no grupo, deixando patente que sua fase como apresentador ficou para trás há muito tempo[...] Um apresentador de um programa como Big Brother obrigatoriamente tem que ser imparcial e não buscar o anti-jogo. Será que Pedro Bial, o apresentador do BBB é a pessoa mais indicada para extrair conceitos morais dos jogadores, posando de bom moço e de guardião do que é ético? [...]

Big Brother $^{16}$ - 20/Marco/2007 15:29:54

Podemos novamente perceber a preocupação de um fã com uma suposta parcialidade na condução do reality show. Apesar da Rede Globo continuamente reafirmar o seu direito de intervir nos acontecimentos na casa do Big Brother sempre que achar necessário, esta não ocorre sem conseqüências. Diferentemente de uma telenovela, ou mesmo de outros reality shows, onde a intervenção da produção é muitas vezes parte constitutiva do formato, no Big Brother ela é frequentemente vista com restrições pela audiência. Naturalmente, não estamos nos referindo àquelas interferências ligadas ao jogo em si, onde provas, tarefas e votações devem ser estipuladas pela produção. Nestes casos, elas constituem a própria cosmologia do Big Brother, e têm a função de criar situações que influenciem na dinâmica de convivência dos integrantes na casa. Estas intervenções são praticadas de maneira explícita, e são muitas vezes antecipadas.

\footnotetext{
${ }^{15}$ Este comentário foi feito no fórum BBB.Lua, durante a sétima edição do reality show.

${ }^{16}$ Big Brother é o login utilizado pelo fã que publicou o comentário no fórum.
} 
Porém, o comentário acima se refere às operações mais sutis, que seriam realizadas de maneira a alterar o juízo de valor da audiência sobre os participantes e acontecimentos do reality show. Elas são percebidas como tentativas de manipulação de informação, portanto vistas com suspeita pelos fãs.

Este depoimento, assim como os demais depoimentos de fãs apresentados neste trabalho, tem uma característica em comum: a desconfiança quanto à forma de condução do programa. Tal sentimento é resultado de diversos fatores. De um modo geral, eles podem ser relacionados a um desequilíbrio entre as expectativas e as realizações do reality show.

Em primeiro lugar, o tipo de construção do ‘outro’ que fazemos quando temos acesso às suas relações dialógicas, sua intimidade, seu cotidiano, enfim, à sua realidade social - mesmo que mediada por câmeras e limitada a um ambiente artificialmente construído - será sempre singular. Ela dependerá, em parte, das expectativas responsivas que criamos em relação a ele, dentro do mundo quotidiano. Já no caso da relação entre o autor de uma obra e o seu personagem, está em curso uma dinâmica que tem por fim dar um sentido acabado a este último. Bakhtin resume esta diferença na citação abaixo:

O autor acentua cada particularidade da sua personagem, cada traço seu, cada acontecimento e cada ato de sua vida, os seus pensamentos e sentimentos, da mesma forma como na vida nós respondemos axiologicamente a cada manifestação daqueles que nos rodeiam; na vida, porém, essas respostas são de natureza dispersa, são precisamente respostas a manifestações particulares e não ao todo do homem, a ele inteiro; e mesmo onde apresentamos definições acabadas de todo o homem - bondoso, mau, bom, egoísta, etc. -, essas definições traduzem a posição prático-vital que assumimos em relação a ele, não o definem tanto quanto fazem um certo prognóstico do que se deve e não se deve esperar dele, ou, por último, trata-se apenas de impressões fortuitas do todo, ou de uma generalização empírica precária; na vida não nos interessa o todo do homem mas apenas alguns de seus atos com os quais operamos na prática e que nos interessam de uma forma ou de outra. (BAKHTIN 2003, :34)

No caso do Big Brother Brasil, podemos imaginar que o descompasso de percepções observado entre os fãs do programa tem parte de sua origem ligada às discrepâncias descritas acima por Bakhtin. Por um lado, a versão para TV aberta se utiliza de técnicas inspiradas na criação ficcional para a delimitação de personagens bem definidos - acabados. Por outro, as versões ‘diretas’ abrem espaço para o diálogo 
axiológico entre a audiência e os integrantes da casa do Big Brother, resultando em relações dinâmicas, não acabadas, e que podem ser constantemente revisitadas por esta audiência.

Depoimentos dos produtores e dos fãs deixam claro que diferentes promessas são feitas para cada plataforma de exibição do reality show, mesmo que isso não aconteça de maneira explícita. Realidade, ficção e jogo são conceitos que se tornam flexíveis na tentativa de vender o programa da melhor maneira possível. Ao mesmo tempo em que os produtores não medem esforços para criar produtos que se aproximem ao máximo dos seus consumidores, eles também correm o risco de perder o controle sobre tais produtos. A ambigüidade do formato se mostra por vezes fonte de disputas para aqueles que possuem uma maior relação afetiva com ele.

Como conseqüência, o estudo dos momentos de recepção do Big Brother nas suas diversas mídias de exibição se torna de suma importância. Através dele, será possível entender um pouco mais os processos de compreensão e interpretação de novos tipos de produtos midiáticos criados intencionalmente de maneira a diminuir as distâncias com seu mercado consumidor.

\section{Bibliografia:}

ANDREJEVIC, Mark. Watching television without pity: the productivity of online fans. Television \& New Media, Vol. 9, n. 1, 2008.

ANG, Ien. Watching Dallas. London: Methuen, 1985.

BAKHTIN, Mikhail. Estética da criação verbal. São Paulo: Livraria Martins Fontes, 2003.

BAZALGETTE, Peter. Billion dollar game. Londres: Time Warner Books, 2005.

CAMPANELLA, Bruno. Investindo no Big Brother Brasil: a análise da economia política de um marco da indústria midiática brasileira. e-Compós, edição 8, 2007a.

. O Big Brother como evento multiplataforma: uma análise dos impasses dos estudos de audiência. In: FREIRE FILHO, João e Herschmann, Micael (orgs). Novos rumos da cultura da mídia: indústrias, produtos, audiências, p. 83-100. Rio de Janeiro: Mauad, 2007.

ECO, Umberto. The open work. Cambridge, MA: Harvard University Press, 1989.

FISKE, John. Television culture. Londres: Routledge, 1987. 
FREIRE FILHO, João. A celebrização do ordinário na TV: democracia radical ou neopopulismo midiático? In: FREIRE FILHO, João e Herschmann, Micael (orgs). Novos rumos da cultura da mídia: indústrias, produtos, audiências, p. 59-82. Rio de Janeiro: Mauad, 2007.

. Reinvenções da resistência juvenil: os estudos culturais e as micropolíticas do cotidiano. Rio de Janeiro: Mauad, 2007.

GRAY, Jonathan et al (eds.). Fandom: identities and communities in a mediated world. Nova York: New York University Press, 2007.

HALL, Stuart. Encoding/decoding. In: HALL, Stuart et al. (eds.), Culture, media, language: working papers in cultural studies, 1972-1979. Londres: Hutchinson, p. 128-138, 1980.

HANSEN, Anders et al. Mass communication research methods. Nova York: Palgrave, 1998.

HARRIS, Cheryl; ALEXANDER, Alison. Theorizing fandom: fans, subculture and identity. Cresskill, NJ: Hampton Press, 1998.

HILLS, Matt. Fan cultures. Londres: Routledge, 2002.

JENKINS, Henry. Textual poachers: television fans and participatory culture. Nova York: Routledge, 1992.

JENSEN, K.J. \& K.E. ROSENGREN. Five Traditions in Search of the Audience. European Journal of Communication, 5(2-3): 207-38, 1990.

JOST, Fraçois. Loft Story: Big Brother in France and the migration of genres. In: MATHIJS, Ernest \& JONES, Janet (eds.). Big Brother International. Londres: Wallflower Paper, 2004.

LEWIS, Lisa (ed.). The adoring audience. Londres: Routledge, 1992.

LIVINGSTONE, Sonia. Making sense of television: the psychology of audience interpretation. Londres: Routledge, 1998.

MACHADO, Arlindo \& VÉLEZ, Marta L. Questões metodológicas relacionadas com a análise da televisão. Revista e-Compós, ediçao 8, abril, 2007.

MILLER, Daniel. Material culture and mass consumption. Oxford: Basil Blackwell 1988.

MORLEY, David. The nationwide audience. Londres: BFI, 1980.

Television, audiences \& cultural studies. Londres: Routledge, 1992.

O GLOBO. “Brincando de Deus”. Entrevista no jornal O Globo publicada no segundo caderno em $08 / 01 / 2007$.

O GLOBO. Segundo Caderno, coluna Patrícia Kogut. de 19/02/2007.

O GLOBO. Segundo Caderno, coluna Patrícia Kogut. de 13/03/2007.

Owens, Justine; Bower, Gordon; \& Black, John. The "soap opera" effect in story recall. Memory and Cognition, 7(3), 185-191, 1979. 
Revista da Associação Nacional dos

Programas de Pós-Graduação em Comunicação

RADWAY, Janice. Reading the romance. Chappell Hill, NC: University of North Carolina Press 1984.

ROSCOE, Jane. Multi-platform event television: reconceptualizing our relationship with television. The Communication Review, vol. 7, p.363-369, 2004.

TINCKNELL, Estella \& RAGHURAM, Parvati. Big Brother: reconfiguring the 'active' audience of cultural studies? European Journal of Cultural Studies, Vol. 5(2), p. 199-215, 2002. 